\title{
Elementos para una aproximación simbólica a "El huésped" de Amparo Dávila
}

\author{
Fortino CORRAL RodrígUEZ* \\ Nubia Uriarte Montoya*
}

\section{Resumen:}

Amparo Dávila, junto con otros autores hispanoamericanos del siglo pasado (Julio Cortázar, Juan José Arreola, Rosario Ferré, Francisco Tario, entre otros) explora en sus cuentos posibilidades de lo fantástico que trascienden los parámetros positivistas en que se basa el relato sobrenatural clásico. El cuento "El huésped" demanda del lector una participación decisiva que va más allá de la duda epistémica entre lo real y lo imaginario que suele provocar el relato fantástico tradicional, pues le ofrece enigmas en el plano simbólico que remiten a problemas de carácter ético y existencial. En esta nota se ensaya una aproximación hermenéutica y con perspectiva de género al cuento de Dávila a partir de la detección significativa de temas y motivos procedentes del mito y de los cuentos de hadas.

Palabras clave:

Amparo Dávila, cuento mexicano fantástico, simbolismo, mito, perspectiva de género.

El cuento "El huésped" pertenece al libro Tiempo destrozado de la escritora mexicana Amparo Dávila, publicado en 1959. Este cuento ofrece un interés especial para los estudiosos del género fantástico contemporáneo ya que se aparta del modelo clásico en el cual la ruptura del orden natural constituye el efecto de sentido más 
importante. De acuerdo con los planteamientos de Todorov, el efecto fantástico se basa en la vacilación que experimenta el lector -colocado en la óptica del protagonista- entre la posibilidad de ofrecer una explicación natural al acontecimiento extraordinario narrado, o admitir que se adscribe al ámbito sobrenatural. La lectura metafórica o alegórica son incompatibles, según este teórico, con el relato fantástico, pues no postulan la realidad de lo referido, condición indispensable de ese tipo del relato.

La cuentística contemporánea, sin embargo, ha explorado nuevas posibilidades de lo fantástico que demandan la articulación de modelos teóricos más incluyentes. La argentina Ana María Barrenechea fue una de las primeras teóricas en advertir que las condiciones impuestas por Todorov dejarían fuera del género buena parte de nuestra literatura. Se trata de textos que conducen a la extrañeza fantástica sin recurrir al hecho estrictamente sobrenatural o soslayándolo cuando ocurre. Jaime Alazraki ha propuesto el término neofantástico para esta variante. El ejemplo conspicuo es La metamorfosis de Kafka, en el cual ocurre que lo extraordinario de la transmutación física que sufre el protagonista pronto pasa a un segundo término y se convierte sólo en un problema doméstico para su familia.

En el contexto hispanoamericano, entre los autores que han explorado opciones novedosas para el relato fantástico contemporáneo, puede mencionarse a Julio Cortázar, Felisberto Hernández, Juan José Arreola, Francisco Tario, Rosario Ferré, Amparo Dávila, entre otros. Algo que caracteriza a este tipo de relato es que lo insólito se desplaza al ámbito existencial: el misterio no se sustenta en la alteración inexplicable del mundo objetivo, sino que es parte constitutiva del ser humano. Este giro auspicia que la mayor carga de sentido descanse en los elementos simbólicos y metafóricos antes que en la infracción del orden natural.

Comencemos con una síntesis del cuento que nos ocupa. La protagonista es una mujer casada que vive recluida, con sus dos hijos pequeños, en una enorme casa ubicada en un pueblo pequeño e incomunicado, lejos de la ciudad. La acompaña su empleada doméstica, quien también tiene un bebé. Aquélla lleva tres años de casada y se siente infeliz. Su marido pasa la mayor parte del tiempo 
en viajes de negocios y la trata con frialdad, "como un mueble" (17). Al regreso de uno de sus viajes, él trae al huésped y lo instala en una habitación; éste permanece en la casa, mientras el marido continúa ausentándose. Las dos mujeres sienten pavor y rechazo por el huésped, el cual acecha a la protagonista y a los niños de ambas. Ocurren algunos incidentes que agravan la situación; el huésped invade el espacio privado de la protagonista y agrede físicamente al niño de la empleada. Finalmente las mujeres deciden actuar: aprovechan una ausencia prolongada del marido y se deshacen del intruso.

El cuento está narrado en primera persona. El personaje habla del profundo malestar emocional que le causa el nuevo habitante de la casa, pero no proporciona información suficiente sobre los atributos concretos de aquél. El lector no sabe si se trata de un ser humano, de un animal, o de una criatura de tipo sobrenatural. Se nos dice que la empleada doméstica también le tiene miedo, pero no podemos saber si es el mismo tipo de miedo; sabemos que a ella (a la empleada) el huésped no la persigue, que es ella quien le lleva las charolas de comida al cuarto y que, de las dos, es la única que sale al mercado; al final, vemos también que es ella, la afanadora, quien marca la pauta para actuar y deshacerse de él.

El texto no postula abiertamente el estatus sobrenatural del huésped ni proporciona elementos suficientes para que el lector lo afirme o lo niegue. José Miguel Sardiñas ha señalado la importancia que tiene la ambigüedad en los cuentos que integran el libro Tiempo destrozado y observa que ésta constituye un aspecto distinto del recurso de vacilación que Todorov propone para el relato fantástico. El investigador puntualiza que la perplejidad que producen los cuentos de Amparo Dávila es producida por la ambigüedad o insuficiencia informativa antes que por la duda fantástica en sí, concerniente al acontecimiento. En efecto, el texto crea un vacío informativo acerca del huésped: le reduce al pronombre él, dispositivo gramatical que puede sustituir tanto el nombre de una persona como el de una cosa. En principio, la sustitución pronominal responde a la función económica de la lengua, pero es importante resaltar que en este caso su uso atiende más bien a un imperativo psicológico del 
hablante: "Guadalupe y yo nunca lo nombrábamos, nos parecía que al hacerlo cobraba realidad aquel ser tenebroso. Siempre decíamos: -ahí está, ya salió, está durmiendo, él, él, él...” (19).

Conviene detenerse un poco más en lo que implica el uso de este pronombre. En la mayoría de las gramáticas del español se establece que los pronombres personales básicos son tres: yo, tú y él. Es natural entonces que la primera acepción del término él remita a persona, es decir, a un ente humano. Sin embargo, Benveniste observa que, desde el punto de vista lingüístico, únicamente los pronombres yo y tú poseen la marca de persona: "La ' $3 \mathrm{a}$. persona' no es una 'persona'; es incluso la forma verbal que tiene por función expresar la no-persona” (164). Las dos primeras se definen por su presencia obligada en el acto comunicativo (yo, el que habla, tú, el que escucha), mientras que la tercera designa necesariamente algo o alguien ausente.

En el cuento el uso de este pronombre tiene justo el efecto de tensionar al máximo esa ambigüedad. En principio se tiñe de humanidad por su pertenencia al paradigma de los pronombres personales, pero al mismo tiempo se le excluye del circuito comunicativo básico en el que se sustenta el estatus mismo de persona. En la repetición "él, él, él" resuena el paradigma "yo, tú, él" a modo de sustitución. El circuito comunicativo supone una alternancia dinámica entre yo y tú como sujetos de enunciación, es decir, en el diálogo ambos se instituyen como yo, como subjetividad individual cada vez que toman la palabra. El pronombre él se caracteriza por esa imposibilidad formal de personalización. La reafirmación del huésped como él resulta entonces muy significativa. No se menciona en el relato ninguna palabra emitida por el huésped: ¿carece de habla o simplemente se omite su discurso? Cuando ataca al niño, ella escucha "el llanto del niño mezclado con extraños gritos" (21). Y cuando lo encierran para que muera de inanición, él "golpeaba la puerta tirándose contra ella, gritaba desesperado, arañaba...” (23), indicios éstos de un comportamiento animalesco. Sus hábitos refuerzan también esta idea: duerme la mayor parte del día y sale al oscurecer; se alimenta sólo de carne, y le acomoda bien el cuarto oscuro y húmedo. En cuanto al aspecto físico, sólo se habla de sus ojos: "grandes 
ojos amarillentos, casi redondos y sin parpadeo, que parecían penetrar a través de las cosas y las personas" (17).

El texto nos obliga, pues, a descartar la hipótesis de que sea un simple animal y nos impide a la vez asumir que se trata de un ser humano común y corriente. El huésped se mantiene como un ser indefinido, un vacío en el sistema del lenguaje. Es, en términos de Rosalba Campra, un silencio incolmable del texto. ${ }^{1} \mathrm{La}$ tendencia al silencio en todo el relato es notoria. En el nivel del texto, la narradora omite información indispensable; en el plano de lo narrado, la casa parece aislada del resto del pueblo, el cual a la vez se halla lejos de la ciudad, incomunicado; en cuanto al marido, la protagonista dice: "Mi marido no tenía tiempo para escucharme, ni le importaba lo que sucediera en la casa. Sólo hablábamos lo indispensable" (20); las labores que ella realiza son solitarias: por las tardes se sienta en los corredores a coser la ropa de los niños o riega las plantas; al parecer no acostumbra charlar con la empleada. En cuanto a los niños, podemos inferir que el mayor tiene apenas dos años de edad, de modo que su capacidad de comunicación verbal es más que limitada, pero además se muestran silenciosos: "A veces pasaban horas callados y muy atentos, tratando de coger las gotas de agua que se escapaban de la vieja manguera" (18); y finalmente, el huésped, del que sólo se mencionan sus gritos inarticulados.

Rosemary Jackson ha llamado la atención sobre la mudez radical o, al menos, gran parquedad verbal, que caracteriza a la mayoría de los seres fantásticos, háblese de vampiros o fantasmas o demonios, etc. En el caso que nos ocupa, podría decirse que la carencia de voz del huésped es uno de los rasgos que contribuyen a que se le perciba como un ser extraño, algo bestial. La fantasticidad radica, pues, en el enigma o misterio que irradia el personaje, y en la atmósfera silenciosa y desolada en que se halla la casa. Sin embargo, el acceso que el lector tiene a este ser enigmático es sólo a través

${ }^{1}$ Rosalba Campra distingue entre los vacíos de indeterminación que normalmente contiene toda narración literaria y los silencios irresolubles que presenta el relato fantástico: "un silencio cuya naturaleza y función consisten precisamente en no poder ser llenado" (52). 
del narrador-personaje, quien lo percibe como "un ser tenebroso". En el narrador-personaje se concentra entonces la mayor parte del sentido.

Desde el comienzo del cuento, la protagonista declara su insatisfacción personal: "llevábamos entonces cerca de tres años de matrimonio, teníamos dos niños y yo no era feliz" (17). Llama la atención el rompimiento de expectativas que se da en la tercera frase. De acuerdo con los roles tradicionales, lo esperable sería "y éramos muy felices". Hay además, un cambio en el sujeto: en las dos primeras afirmaciones, el sujeto corresponde a nosotros, y la tercera se limita a yo, lo cual hace pensar que la causa del malestar no proviene del exterior sino de la relación entre yo y nosotros. Tenemos pues una situación insatisfactoria pero estable que será perturbada con la llegada del huésped.

La presencia de este ser tenebroso hace más patente para la mujer la ausencia del esposo, su despotismo, y el estado de encierro en que ella vive se acentúa. Esto nos remite al acendrado motivo literario de la mujer prisionera en una torre, tema que se remonta al mito de Dánae, encerrada por su padre, y que se repite en textos medievales, hasta llegar a nuestros días en cuentos de hadas como Rapunzel, La Bella y la Bestia, Barba Azul, etc., en películas como Shrek I y en videojuegos como Zelda, el cual consiste justamente en "rescatar" a la princesa de ese nombre; incluso el rústico plomero Mario Bros camina en esa dirección.

Linda Zee advierte que "the traditional gothic theme of a woman somehow trapped or confined within a house or room remained a favourite among woman writing in patriarchal Spanish American societies, long after European women such as Mary Shelley had at least partially surmounted social and cultural restrictions and come into their own as writers" (Zee 90). ${ }^{2}$ Advierte también que estas escritoras introducen el mito en sus cuentos como un recurso eficaz para deconstruir y analizar las jerarquías, instituciones y roles sociales establecidos por el orden patriarcal.

2 "El tema gótico tradicional de la mujer atrapada o confinada en una casa o habitación continuó siendo uno de los favoritos entre las mujeres que escribían en 
En el cuento que nos ocupa aparecen de manera subrepticia varios elementos que nos permiten formular alguna correspondencia con esa imagen mítica o legendaria de la princesa encerrada en la torre. La casa rebasa en tamaño las proporciones normales de una casa-habitación, es cuadrangular y se halla lejos de la ciudad: "La casa era muy grande, con un jardín en el centro y los cuartos distribuidos a su alrededor" (18). La forma cuadrada o rectangular se infiere del espacio asignado al huésped: "Desde el primer día mi marido le asignó el cuarto de la esquina" (18). En esa casa ella realiza labores que se acercan mucho al trabajo forzado: “Tener arreglada una casa tan grande y cuidado el jardín, mi diaria ocupación de la mañana, era tarea dura" (18). Y, por último, su carácter de prisionera se lo da el hecho de que no tiene los medios para escapar: "Pensé entonces en huir de aquella casa, de mi marido, de él... pero no tenía dinero y los medios de comunicación eran difíciles. Sin amigos ni parientes a quienes recurrir, me sentía tan sola como un huérfano" (21).

La arquitectura de la casa "con un jardín en el centro y los cuartos distribuidos alrededor" con corredores cubiertos de enredaderas, se adentra en una dimensión simbólica. Sobre el simbolismo de la casa, el antropólogo Gilbert Durand considera que desempeña la función de un microcosmos secundario situado entre el microcosmos del cuerpo humano y el cosmos. Advierte que la casa deviene fácilmente en laberinto pero "es un laberinto tranquilizador, amado, pese al ligero terror que puede producir aún su misterio" (231). En efecto, en el cuento de Amparo Dávila, la casa conjuga rasgos laberínticos. Un laberinto en el que hay también un monstruo amenazante.

El espacio preferido por la mujer es el jardín: "Yo amaba mi jardín", dice; y más adelante agrega: "En el jardín cultivaba crisantemos, pensamientos, violetas de los Alpes, begonias y heliotropos" (18). El jardín es el espacio de la intimidad, una afirmación y una

las sociedades patriarcales hispanoamericanas, mucho después de que las mujeres europeas como Mary Shelley habían superado, al menos parcialmente, restricciones sociales y culturales y se habían convertido en escritoras." Traducción nuestra. 
extensión del yo. Este jardín está rodeado de corredores "que protegían las habitaciones del rigor de las lluvias y del viento que eran frecuentes" (18). Esta configuración concéntrica de la casa remite también al mandala junguiano, en el cual se conjugan las fuerzas que amenazan la integridad psíquica y los recursos de protección que le asisten. El jardín, en este caso, se ve seriamente amenazado por el monstruo que ocupa el cuarto de la esquina y se pasea por los corredores. La mujer se ve obligada a abandonarlo y refugiarse en su cuarto, pero aun ahí sufre el acecho implacable del huésped: "Cuando salía de su cuarto comenzaba la más terrible pesadilla que alguien pueda vivir. Se situaba siempre en un pequeño cenador, enfrente de la puerta de mi cuarto" (19).

¿Qué tipo de peligro representa el huésped? La narradora advierte que la amenaza pesa especialmente en ella, no tanto en la sirvienta: "Creo que ignoraba por completo a Guadalupe, nunca se acercaba a ella ni la perseguía. No así a los niños y a mí. A ellos los odiaba y a mí me acechaba siempre" (19). En cuanto a los niños, en cambio, el peligro se cierne por igual entre los de una y otra. El temor de que ataque a las criaturas resulta plenamente justificado cuando él golpea cruelmente al niño de Guadalupe, aprovechando una ausencia de ésta; la protagonista se lo quita y lo golpea con una tranca. El marido, por su parte, subestima los ruegos desesperados de su esposa de que se lo lleve porque puede matar a los niños. La respuesta que le da constituye un buen apoyo para quien persigue una lectura realista del texto: "Cada día estás más histérica, es realmente doloroso y deprimente contemplarte así... te he explicado mil veces que es un ser inofensivo" (21). ¿Podría ser todo esto mera alucinación paranoica de la mujer? Técnicamente, es una lectura que no puede descartarse. Sin embargo, tampoco puede negarse la existencia de un conflicto conyugal que provoca estas alucinaciones, en caso de ser tales.

Tenemos, pues, un marido que pasa la mayor parte del tiempo fuera de la casa y que instala en ésta un ser que es todo ojos. Hemos dicho anteriormente que la única descripción física que se da del huésped se limita a esos ojos amarillos, enormes y redondos. El 
marido no ofrece ningún argumento para justificar la estancia de ese ser en la casa; simplemente lo impone en contra de la voluntad de su esposa; la noche en que lo trae, ella le suplica que no la someta a la tortura de su compañía, pero él se mantiene firme en su decisión: “'Es completamente inofensivo” -dijo mi marido mirándome con marcada indiferencia. 'Te acostumbrarás a su compañía y si no lo consigues..."” (17). La presencia del huésped representa, pues, en primer término, la autoridad del marido. Está ahí porque él lo manda. Se establece, pues, una identidad metonímica entre éste y aquél: uno es prolongación o extensión del otro. Este continum se manifiesta, al mismo tiempo en forma de dicotomías complementarias: la ausencia prolongada de uno / la presencia abrumadora del otro; la mirada indiferente del marido / la mirada penetrante del huésped. Luce Irigaray advierte que "el asedio de la mirada no está tan privilegiado en las mujeres como en los hombres. El ojo, más que los demás sentidos, objetiva y domina” (Citado en Oyarzun 188).

Por otra parte, Benveniste observa que en el pronombre él está presente la marca de género, a diferencia de lo que ocurre con los pronombres personales yo y tú. En la repetición "él, él, él” que hace la mujer, se enfatiza el género masculino como la nota más destacada del ser referido. El terror que vibra en su pronunciación delata la ambigüedad de ese él ambiguo que alcanza tanto al monstruo como al marido ausente, y que les identifica.

En el esposo protector se oculta, pues, el déspota, y en el miedo sobrenatural que experimenta la amada se oculta el odio inconfesable contra el amante opresor. Bajo la apariencia externa de la reina del hogar burgués, subyace la princesa prisionera en tosca torre custodiada por dragones. ¿Pero quién ha de rescatarla?

Es altamente significativo que en otros cuentos fantásticos escritos por mujeres sobre mujeres casadas como "La culpa es de los tlaxcaltecas" de Elena Garro, "El árbol” de María Luisa Bombal y "La muñeca menor" de Rosario Ferré, entre otros, ocurre que son las propias protagonistas las que llevan a cabo su escape, o en su defecto, lo hacen con ayuda de otra mujer. Tanto en "La culpa..." como en "El huésped" ocurre que la empleada doméstica llega a 
ser el aliado clave para la liberación, es decir, se supera la jerarquía ama/criada mediante un proceso de identificación solidaria.

En el cuento vemos cómo los acontecimientos adversos van acercando a las dos mujeres. En un principio habitan piezas separadas y cada quien hace el trabajo que le corresponde. A partir de la llegada del huésped, comienza a darse un mayor acercamiento que se traduce en protección mutua: "Cuando los niños se dormían, Guadalupe me llevaba la cena al cuarto. Yo no podía dejarlos solos sabiendo que [el huésped] se había levantado o estaba por hacerlo" (19). A su vez, ella cuida al niño Martín cuando Guadalupe sale al mercado. El acontecimiento definitivo sucede cuando el huésped ataca a este niño y la protagonista lo salva. "Temí que Guadalupe se fuera y me dejara sola. Si no lo hizo, fue porque era una mujer noble y valiente que sentía gran afecto por los niños y por mí. Pero ese día nació en ella un odio que clamaba venganza" (21). Las dos mujeres concluyen que deben hacer algo para acabar con esta situación. Guadalupe y su niño se mudan al cuarto de la protagonista y ellas preparan el plan durante la noche para deshacerse del huésped. Aprovechan una de las ausencias prolongadas del marido para ejecutar su plan: sellan la puerta del cuarto del huésped con tablones y clavos. Durante dos semanas escuchan angustiadas sus terribles gritos hasta que vuelve el silencio.

En resumen, el simbolismo del cuento se estructura como un ideograma complejo sobre los fundamentos jerárquicos y asimétricos que imperan en los roles domésticos. La mujer, sujeta al área de la casa, no es dueña de ese espacio, sino que forma parte de él como una pertenencia más del gran propietario ausente. Tal jerarquía se manifiesta en el plano lingüístico como la supremacía de él, sobre el binomio equitativo constructor de subjetividades yo / tú, en que presuntamente se funda la pareja. Atendiendo al desarrollo de la narración, el esquema pronominal experimenta los siguientes cambios: el nosotros inicial que incluía a la protagonista y a su marido presupone un yo / tú en equilibrio; sin embargo, el yo narrador experimenta alguna inequidad ("no era feliz"). La llegada del huésped precipita la crisis y transmuta el binomio yo / tú en un yo / él, donde él no 
dialoga sino ordena e impone su autoridad. El estado final, el nuevo equilibrio, consiste en el restablecimiento de un nuevo yo / tú que se da en el diálogo solidario entre el ama y la empleada doméstica; es el único pasaje que aparece en forma de diálogo en el texto:

-Esta situación no puede continuar -le dije un día a Guadalupe.

-Tendremos que hacer algo y pronto -me contestó.

- ¿Pero qué podemos hacer las dos solas?

-Solas, es verdad, pero con un odio...

Sus ojos tenían un brillo extraño. Sentí miedo y alegría. (23)

\section{Obras citadas}

Alazraki, Jaime. “¿Qué es lo neofantástico?” En Teoría de lo fantástico. Comp. David Roas. Madrid: Arco/Libros, 2001. 265-282.

Barrenechea. "Ensayo de una tipología de la literatura fantástica." Revista Iberoamericana 80 (1972): 391-403.

Benveniste, Émile. Problemas de lingüística general. I. Trad. Juan Almela. 10a. ed. México: Siglo xxi, 1982.

Campra, Rosalba. "Los silencios del texto en la literatura fantástica." En El relato fantástico en España e Hispanoamérica. Ed. Enriqueta Morillas Ventura. Madrid: Sociedad Estatal Quinto Centenario/Siruela, 1991. 49-73.

Dávila, Amparo. "El huésped." Muerte en el bosque. México: SEP/FCE, 1985. $17-23$

Durand, Gilbert. Estructuras antropológicas de lo imaginario. Introducción a la arquetipología general. Madrid: Taurus, 1981.

Jackson, Rosemary. Fantasy: The literature of subversión. New York: Routledge, 2003.

Oyarzún, Kemy. "Identidad femenina, genealogía mítica, historia: Las manos de mamá, de Nellie Campobello." Revista de Crítica Literaria Latinoamericana 22.43-44 (1996): 181-200. 
Sardiñas, José Miguel. "Sobre la ambigüedad en Tiempo destrozado, de Amparo Dávila." Lo fantástico y sus fronteras. Eds. Ana María Morales, José Miguel Sardiñas y Luz Elena Zamudio. México: BUAP, 2003. 223-32

Todorov, Tzvetan. Introducción a la literatura fantástica. Trad. Silvia Delpy. México: Editorial Coyoacán, 1994.

Zee, Linda. "The Boundaries of the Fantastic: The Case of Three American Women Writers." Tesis doctoral. Indiana University, 1993. 